8 Jadad AR, Moore RA, Carroll D, Jenkinson C, Reynolds DJM, Gavaghan DJ, et al. Assessing the quality of reports of randomized clinical trials: is blinding necessary? Control Clin Trials 1996;17:1-12.

9 Schulz KF, Chalmers I, Hayes RJ, Altman DG. Empirical evidence of bias: dimensions of methodological quality associated with estimates of treatment effects in controlled trials. JAMA 1995;273:408-12.

10 Cho MK, Bero LA. The quality of drug studies published in symposium procedings. Ann Intern Med 1996;124:485-9.

11 Bartko JJ. General methodology. II. Measures of agreement: a single procedure. Stat Med 1994;13:737-45.

12 Follman D, Elliott P, Sul I, Cutler J. Variance imputation for overviews of clinical trials with continuous response. J Clin Epidemiol 1992;45:769-73.

13 Hedges LV, Olkin I. Statistical methods for meta-analysis. Orlando, FL: Academic Press, 1995.

14 Begg CB, Mazundar M. Operating characteristics of a rank correlation test for publication bias. Biometrics 1994;50:1088-1101.

15 Egger M, Davey Smith G, Schneider M, Minder C. Bias in meta-analysis detected by a simple, graphical test. BMJ 1997;315:629-34.

16 Light RS, Pillemar DB. Summing up: the science of reviewing research. Cambridge, MA: Havard University Press, 1984

17 Hedges LV. Modelling publication selection effects in meta-analysis. Stat Sci 1992;7:246-55.

18 Taylor S, Tweedie R. Trim and fill: a simple funnel plot based method of testing and adjusting for publication bias in meta-analyses. Fort Collins, CO: Colorado State University, 1998

19 Westley CR, Cotton EK, Brook JG. Nebulized racemic epinephrine by IPPB for the treatment of croup: a double-blind study. Am J Dis Child $1978 ; 132: 484-7$
20 Moher D, Pham B, Jones A, Cook DJ, Jadad AR, Moher M, et al. Does the poor quality of reports of randomized trials exaggerate estimates of intervention effectiveness reported in meta-analysis? Lancet 1998;352:609-13.

21 Moher D, Fortin P, Jadad AR, Juni P, Klassen T, LeLorier J, et al. Completeness of reporting of trials published in languages other than English: implications for conduct and reporting of systematic reviews. Lancet 1996;347:363-6.

22 Klassen TP. Glucocorticoids in the treatment of croup: barking up the right tree. Can Med Assoc J 1998;159:1121-2.

23 Geelhoed GC. Sixteen years of croup in a Western Australian teaching hospital: effects of routine steroid treatment. Ann Emerg Med 1996;28:621-6.

24 Martensson B, Nilson G, Torbjar J. The effect of corticosteroids in the treatment of pseudo-croup. Acta Otolaryngol 1960;158(suppl):62-71.

25 Novik A. Corticosteroid treatment of non-diptheritic croup. Acta Otolaryngol 1960;158(suppl):20-3.

26 Sussman S, Grossman M, Magoffin R, Schieble J. Dexamethasone (16 alpha-methyl, 9 alpha-fluoroprednisolone) in obstructive respiratory tract infections in children. Pediatrics 1964:34:851-5.

27 Guyatt GH, Kirshner B, Jaeschke R. Measuring health status: what are the necessary measurement properties? J Clin Epidemiol 1992;45:1341-5.

28 Klassen TP, Rowe PC. The croup score as an evaluative instrument in clinical trials [abstract]. Arch Pediatr Adolesc Med 1995;149:60.

(Accepted 2 June 1999)

\title{
Predictors and consequences of unemployment among construction workers: prospective cohort study
}

Päivi Leino-Arjas, Juha Liira, Pertti Mutanen, Antti Malmivaara, Esko Matikainen

Department of
Epidemiology and
Biostatistics, Finnish
Institute of
Occupational
Health, FIN-00250
Helsinki
Päivi Leino-Arjas
senior researcher
Pertti Mutanen
statistician
Work Ability
Centre, Finnish
Institute of
Occupational
Health
Juha Liira
senior consultant
Department of
Occupational
Medicine, Finnish
Institute of
Occupational
Health
Antti Malmivaara
assistant chief medical
officer
Local Government
Pensions Institution
Finland,
Albertinkatu 34,
FIN-00100, Helsinki
Esko Matikainen
chief medical officer
Correspondence to:
P Leino-Arjas
plei@occuphealth.fi

BMJ 1999;319:600-5

\author{
Abstract \\ Objective To study predictors and consequences of \\ unemployment. \\ Design Prospective cohort study. \\ Setting 11 construction companies in southern \\ Finland.
}

Participants 586 male employees, aged 40-59 years at baseline in 1991 and not retired during a 4 year follow up.

Main outcome measures Long term unemployment, stress symptoms, disease, alcohol consumption, exercise activity, and body mass index.

Results In a multiple logistic regression model, long term unemployment ( $>24$ months $v \leqslant 24$ months) was predicted by age $50-54$ years $v 40-44$ years (odds ratio $2.0,95 \%$ confidence interval 1.1 to 3.7$), \leqslant 3$ years' employment in the present job $(3.1,1.9$ to 5.1$)$, previous unemployment (2.1, 1.2 to 3.8$)$, being single (1.8, 1.1 to 3.1$)$, current smoking $(2.6,1.4$ to 4.7$)$, high alcohol consumption (2.1, 1.1 to 4.3 ), body mass index $<23 \mathrm{~kg} / \mathrm{m}^{2} v 23-29 \mathrm{~kg} / \mathrm{m}^{2}$ (2.4, 1.3 to 4.4 ), frequent stress symptoms (2.0, 1.2 to 3.2), mental disorders (7.8, 1.5 to 40.0$)$, and skin diseases (2.0, 1.0 to 3.9$)$. Workers who were unemployed long term reported increased stress (2.1, 1.2 to 3.5) but fewer incident diseases (0.6, 0.4 to 0.9$)$, decreased alcohol consumption $(2.9,1.6$ to $5.2)$, increased exercise (1.9, 1.2 to 3.0$)$, and increased body mass index (2.3, 1.3 to 4.0$)$ compared with the rest of the cohort.

Conclusions The workers' perceptions of work did not predict unemployment. Health based selection to long term unemployment was shown. Smoking and high alcohol consumption predated unemployment, but favourable lifestyle changes were observed among the unemployed workers. Stress predicted unemployment, which further increased the stress.

\section{Introduction}

A relation between unemployment and ill health seems established: several studies reported mental distress, ${ }^{1-3}$ frequency of use of health care, ${ }^{4-6}$ and mortality $^{5-8}$ to be high among unemployed individuals. The mechanisms of this relation are not, however, obvious. It is possible that $(a)$ poor health leads to a low status on the labour market and increases the risk of unemployment, (b) job loss and unemployment have adverse effects on health, or $(c)$ both mechanisms are active. $^{9}$

The ideal way to investigate predictors and consequences of unemployment would be to conduct a prospective study of a cohort of employed people at baseline, with a subgroup becoming unemployed, and who were followed up over a long period. Studies on the effects of factory closure provide an option, but a suitable comparison group is difficult to find and potential participants are usually alerted to the possibility of closure around the same time as the researchers. ${ }^{10} \quad$ Socioeconomically disadvantaged people are at a high risk of both health problems and unemployment; it has not always been possible to control for this source of confounding. It seems plausible that characteristics apart from health-for example, lifestyle or attitudes towards work and family-would play a role in unemployment or re-employment.

We studied some predictors of unemployment in a cohort of construction workers during Finland's recession in the early 1990s. We also studied changes in health and lifestyle with duration of unemployment 
and whether some changes resulted from increased economic strain while jobless.

\section{Participants and methods}

\section{Data collection}

We compiled our baseline data by interviewing 961 men employed in the construction industry in Finland in $1991 .{ }^{11}$ We approached all blue collar workers, aged 40-64 years, of 11 construction companies with occupational health departments in the Helsinki metropolitan region or in Häme, southern Finland; 947 men (98.5\%) agreed to participate. We were given staff lists for each worksite, but a few men could not be traced owing to change of worksite. Interviews at baseline and follow up lasted 45 minutes. Baseline interviews were conducted at the worksites by nurses trained for the purpose. Responses were entered into a computer during the interview. Four years later, 741 men $(77.1 \%)$ were available for interview conducted by telephone by the Kuopio Regional Institute of Occupational Health.

We restricted our analyses to men aged 40-59 years at baseline (707 participants). We excluded 104 participants who retired during follow up and 17 participants with missing data on duration of unemployment, leaving 586 men.

\section{Unemployment}

We dichotomised the number of times workers were unemployed during the 5 years preceding the baseline interview $(0$ or $\geqslant 1)$. Participants were asked how many months they had been unemployed or temporarily laid off for each year since the beginning of 1991 . Unemployment was measured as the total number of months. Owing to the skewed distribution of this variable, we defined duration of unemployment as long term (more than 24 months' redundancy during follow up) and short term (joblessness for 1-24 months during follow up).

\section{Sociodemographic variables and economic situation}

Being single was defined as unmarried, separated, or widowed ( $v$ married or cohabiting); vocational training (yes or no) included training at work and at school; and occupational skills (skilled or semiskilled) were on the basis of job titles. The men were asked if their economic situation was fair, average, or poor.

\section{Lifestyle and health}

We ascertained how much physical exercise the men took during leisure time by asking how often they undertook such exercise for at least half an hour so that they got at least slightly out of breath and started to sweat (classified as never to 2-3 times a month $v$ once a week to daily).

Smoking habits, inquired of at baseline only, were classified as never smoker, stopped smoking, and current smoker. We calculated an alcohol consumption index by converting separately assessed amounts of beer, wine, and spirits into absolute alcohol (g/day). An alcohol free period of 1 year was recorded as $0 \mathrm{~g}$ alcohol. The rank correlation coefficient between the alcohol consumption indices of 1991 and 1995 was 0.71 .
The index was used both as a continuous variable (range 0-6.57) and as a dichotomised variable (index class represented upper $10 \%$ of the variable distribution). Body mass index $\left(\mathrm{kg} / \mathrm{m}^{2}\right)$ assessed the extent of overweightness.

The participants were asked about current diseases diagnosed by a physician. We considered disorders that were musculoskeletal, cardiovascular, respiratory, mental, neurological and sensory, gastrointestinal, skin, neoplastic, haematological, and urogenital. We also calculated the number of diseases $(0,1,2$, or $\geqslant 3)$.

Musculoskeletal symptoms (Cronbach's $\alpha=0.85$ ) were scored by asking participants if they had had aches, stiffness, tenderness on movement, numbness, or pain at particular sites during the past year (14 items: unilateral or bilateral neck, occipital region; radiation of neck pain to the arm; shoulder, upper arm; elbow, lower arm; wrist, hand, fingers; thoracic spine; low back; radiation of low back pain to lower limb; hip joint; thigh; knee; calf; ankle, foot; sole, toes): never or rarely (score 1), occasionally (2), rather often (3), and often or continuously (4).

Stress symptoms $(\alpha=0.75)$ were scored as for musculoskeletal symptoms by asking participants whether they had had particular symptoms recently (16 items: headache; irritability or fits of anger; tension or nervousness; loss of energy; dyspnoea without physical exertion; excessive perspiration without physical effort; tremor of hands; rapid or irregular heart beats; dizziness; reduced libido; sleeping difficulties; nightmares; diarrhoea or irregular bowel function; abdominal pain or acid troubles; nausea or vomiting; loss of appetite.)

\section{Work related variables}

We asked participants how many years they had been in their present employment, and whether they had been unemployed or temporarily laid off during the past 5 years $(n o=1$, at least once $=2)$. Physical strain was assessed by asking whether the work required too much in relation to the participants' ability (sum score $(\alpha=0.80)$ on basis of five items-physical work and use of muscle power, lifting and carrying, abrupt efforts, repetitive work movements, and stooped and twisted work postures). Participants were asked whether job satisfaction was impaired by rushed and tight schedules, forced work pace, lack of influence, lack of recognition, or interference from supervisors. Scores were summed to give a psychosocial strain score $(\alpha=0.55)$. Participants were also asked to describe their work ability using a visual analogue scale from 0 (worst) to 10 (best).

Attitude to work was assessed by asking participants to select the statement most relevant to their job: (a) my job is like any other-I do my job but the only thing that matters is the money; and (b) it is a job that means something to me-in addition to the income, I get personal satisfaction out of it. Participants were asked to describe the significance of their home and family and pastime activities (classified as not significant $v$ fairly significant, or very significant).

\section{Statistical methods}

We examined separately age adjusted odds ratios of the predictor variables for both short term (1-24 $v 0$ months) and long term (>24 v $\leqslant 24$ months) 
Table 1 Distribution of number of months men were unemployed during follow up

\begin{tabular}{lc} 
Months unemployed & No $(\%)$ of men $(\mathbf{n}=\mathbf{5 8 6})$ \\
\hline 0 & $125(21.3)$ \\
\hline $1-6$ & $124(21.2)$ \\
\hline $7-12$ & $100(17.1)$ \\
\hline $13-24$ & $122(20.8)$ \\
\hline $25-47$ & $115(19.6)$
\end{tabular}

unemployment. Age was classified as 40-44, 45-49, 50-54, and 55-59 years. The associations between determinants and unemployment were studied by using smoothers (cubic B splines in S-Plus software). ${ }^{12}$ We especially studied the functional form of the relation, linearity, and optimal cut off points. The classification for body mass index was on the basis of smoothing, but most classifications were made according to the frequency distribution of the variable (mostly about one third put in the index class).

Multiple logistic regression analyses included independent variables that were significantly associated with unemployment when allowing for age (we did not include the variable of home and family owing to a high covariance with marital status). The final models included predictors significantly associated with unemployment.

Duration of unemployment was classed into four equally sized groups (0, 1-8, 9-20, 21-47 months); long term unemployment versus other was also used. Allowing for age, we performed logistic regression analyses of the relation between duration of unemployment and changes to health and lifestyle. Disease variables were dichotomised ( $0 v \geqslant 1$ diseases) when necessary. The index category of the other variables represented the upper or lower decile of the variable difference.

To account for the possibility that a change in the employee's economic situation would have mediated some effects of unemployment, we compared models with and without the trichotomised difference of the variable describing the participant's economic situation.

\section{Results}

At follow up, 241 men (41.1\%) were employed, 293 $(50.0 \%)$ unemployed, $21(3.6 \%)$ laid off, 18 (3.1\%) on sick leave, and $13(2.2 \%)$ reported other situations. Four out of five participants had been unemployed during follow up-mean total duration 12 months (table 1).

\section{Predictors of unemployment}

The highest odds ratios of unemployment were in the 50-54 year old age group (table 2). The age adjusted odds ratios of factors measured at baseline, with long term unemployment during follow up, are presented in table 2, and the multivariate model of the predictors is shown in table 3. Subsequent unemployment was associated with previous unemployment, duration of present employment contract, being single, heavy alcohol consumption, and current smoking, but not physical or psychosocial strain at work, work ability, or valuation of pastime activities.

Frequent symptoms of stress was predictive of long term unemployment (table 2). Participants with diagnosed mental, gastrointestinal, skin, or neurological or sensory disorders had an increased risk of long term unemployment. The mental disorders were almost all at the level of neurosis ( 7 cases; age adjusted odds ratio 10.6, 95\% confidence interval 2.0 to 55.5). The most prominent disorders predictive of unemployment were gastric or duodenal ulcers (27 cases; $3.5,1.6$ to 7.7 ), allergic eczema (25 cases; $2.4,1.03$ to 5.6 ), and ocular diseases when diffraction abnormalities were excluded (15 cases; 3.7, 1.3 to 10.4).

Table 3 shows the final model of long term unemployment. At a probability of 0.22 , the model (sensitiv-

Table 2 Association between baseline measurements and long term unemployment (>24 months) during follow up (odds ratios adjusted for age group)

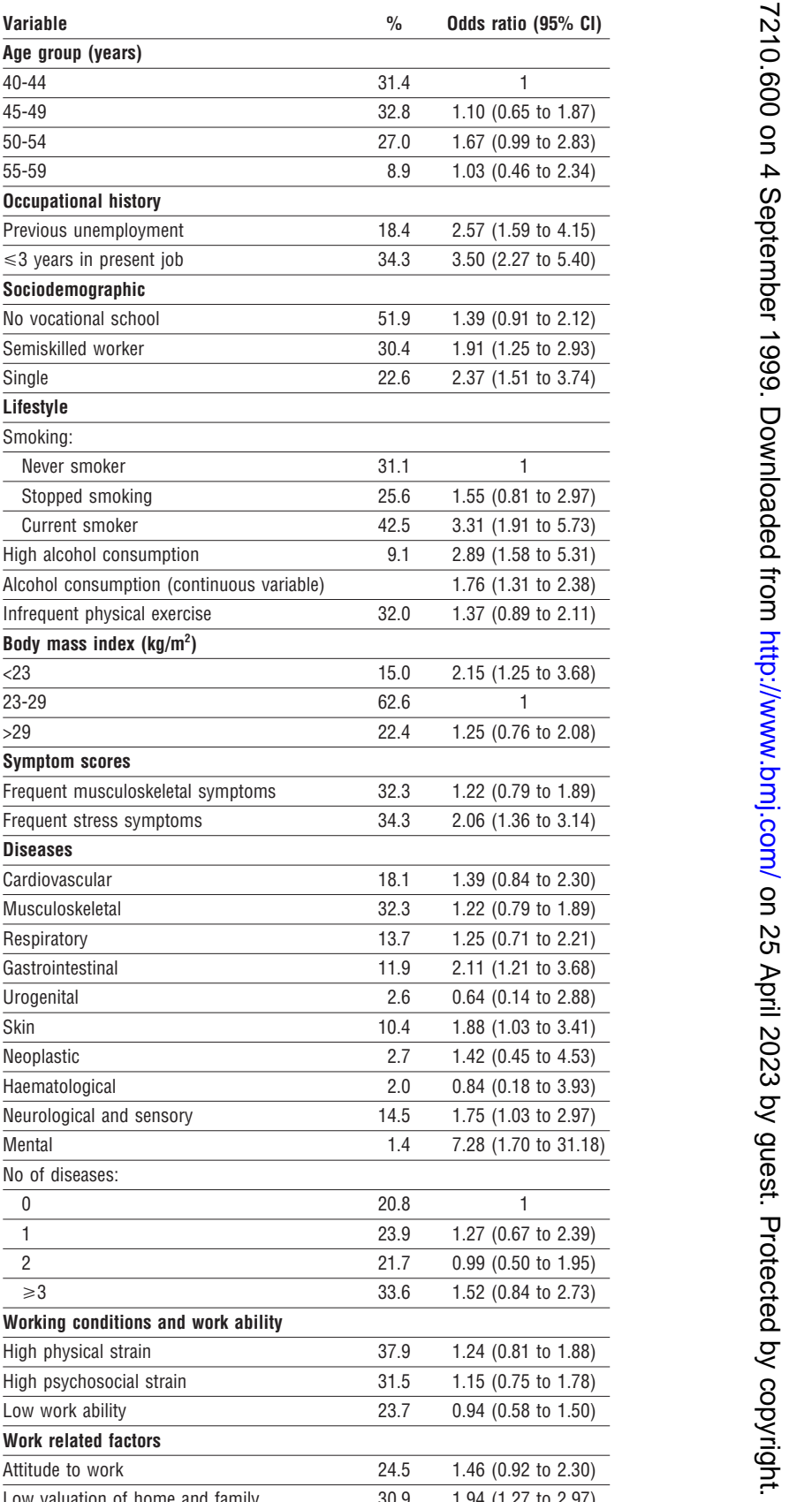

\begin{tabular}{lll}
\hline Low valuation of home and family & 30.9 & $1.94(1.27$ to 2.97$)$ \\
\hline High valuation of pastime activities & 33.4 & $1.53(0.97$ to 2.42$)$ \\
\hline
\end{tabular}


ity $58 \%$ and specificity $78 \%$ ) correctly classified $74 \%$ of the cases.

The final multivariate model of short term unemployment included: age group (only men aged 55-59 years differed significantly from those aged 40-44 years; $3.56,1.29$ to 9.83 ), having been in the present job for no more than 3 years $(1.92,1.16$ to 3.17), and alcohol consumption (continuous variable: $2.41,1.27$ to 4.60 ). The predictive performance of the model at the cut off point of 0.74 was sensitivity $50 \%$, specificity $61 \%$, and overall correct percentage 53 .

\section{Consequences of unemployment}

Participants unemployed long term reported an increased frequency of exercise, decreased alcohol consumption, and increased body mass index compared with the rest of the cohort (table 4); the dependencies of frequency of exercise and alcohol consumption on duration of unemployment were monotonous (table 5).

Participants employed long term reported increased stress but fewer incident diseases compared with the rest of the cohort (tables 4 and 5); scores for musculoskeletal symptoms did not change significantly with unemployment. We observed no associations between specific diseases and duration of unemployment.

In a logistic regression model including the length of unemployment, change in the participant's eco-

Table 3 Multivariate logistic regression model of predictors of long term unemployment ( $>24$ months)

\begin{tabular}{ll}
\begin{tabular}{l} 
Variable \\
\hline Age (years):
\end{tabular} \\
\hline $40-44$ & 1 \\
\hline $45-49$ & $1.12(0.62$ to 2.03$)$ \\
\hline $50-54$ & $2.00(1.08$ to 3.71$)$ \\
\hline $55-59$ & $1.39(0.55$ to 3.52$)$ \\
\hline Previous unemployment & $2.13(1.20$ to 3.80$)$ \\
\hline$\leqslant 3$ years in present job & $3.09(1.88$ to 5.08$)$ \\
\hline Single & $1.84(1.09$ to 3.12$)$ \\
\hline Smoking: & 1 \\
\hline Never smoker & $1.98(0.99$ to 3.97$)$ \\
\hline Stopped smoking & $2.58(1.42$ to 4.69$)$ \\
\hline Current smoker & $2.11(1.05$ to 4.25$)$ \\
\hline High alcohol consumption & \\
\hline Body mass index $\left(\mathrm{kg} / \mathrm{m}^{2}\right):$ & $2.35(1.26$ to 4.36$)$ \\
\hline$<23$ & 1 \\
\hline $23-29$ & $1.71(0.96$ to 3.02$)$ \\
\hline$>29$ & $1.97(1.22$ to 3.21$)$ \\
\hline Frequent stress symptoms & $7.75(1.51$ to 39.93$)$ \\
\hline Mental disorder & $1.99(1.01$ to 3.93$)$ \\
\hline Skin disease
\end{tabular}

Table 4 Long term unemployment ( $>24$ months) during follow up in relation to changes in lifestyle variables, body mass index, symptom scores, and incident diseases (comparison group was all other participants). Odds ratios adjusted for age group

\begin{tabular}{lc} 
Variable & Odds ratio $\mathbf{( 9 5 \%} \mathbf{~ C l )}$ \\
\hline Increase in exercise frequency $^{*}$ & $1.91(1.24$ to 2.96$)$ \\
\hline Decrease in alcohol consumption† & $2.88(1.59$ to 5.22$)$ \\
\hline Increase in body mass index & \\
\hline Increase in stress symptoms & \\
\hline Decrease in musculoskeletal symptoms $\dagger$ & $2.28(1.30$ to 4.00$)$ \\
\hline Incident diseases & $2.06(1.23$ to 3.47$)$ \\
\hline
\end{tabular}

${ }^{*}$ Index category is upper tenth of score difference. †Index category is lower tenth of score difference.
Table 5 Multivariate logistic regression analyses (adjusted for age group) for duration of unemployment and change of participants' economic situation during follow up in relation to changes in stress symptoms, disease morbidity, body mass index, and alcohol consumption. Values are odds ratios ( $95 \%$ confidence intervals)

\begin{tabular}{|c|c|c|c|c|}
\hline Variable & $\begin{array}{l}\text { Increase in stress } \\
\text { symptoms* }\end{array}$ & Incident diseases & $\begin{array}{l}\text { Increase in body } \\
\text { mass index* }\end{array}$ & $\begin{array}{l}\text { Decrease in alcohol } \\
\text { consumptiont }\end{array}$ \\
\hline \multicolumn{5}{|c|}{ No of months unemployed } \\
\hline 0 & 1 & 1 & 1 & 1 \\
\hline $1-8$ & $1.39(0.61$ to 3.15$)$ & $1.16(0.71$ to 1.88$)$ & $0.59(0.25$ to 1.40$)$ & $3.57(0.99$ to 12.93$)$ \\
\hline $9-20$ & $1.70(0.76$ to 3.79$)$ & $0.81(0.49$ to 1.34$)$ & $1.05(0.47$ to 2.34$)$ & $5.11(1.41$ to 18.56$)$ \\
\hline $21-47$ & 2.09 (0.95 to 4.60$)$ & 0.67 (0.40 to 1.13$)$ & 1.89 (0.88 to 4.06$)$ & 8.04 (2.28 to 28.38) \\
\hline \multicolumn{5}{|c|}{ Economic situation } \\
\hline No change & 1 & 1 & 1 & 1 \\
\hline Better & $0.50(0.06$ to 3.90$)$ & 0.82 (0.33 to 2.05$)$ & $1.02(0.22$ to 4.66$)$ & 2.00 (0.42 to 9.60$)$ \\
\hline Worse & $2.13(1.30$ to 3.50$)$ & 1.05 (0.73 to 1.52$)$ & 0.89 (0.50 to 1.57$)$ & 1.33 (0.74 to 2.42$)$ \\
\hline
\end{tabular}

*Index category is upper tenth of score difference.

tIndex category is lower tenth of score difference.

nomic situation during follow up, and age group as independent variables, increased economic hardship was associated with increased stress (table 5). The association between duration of unemployment and increased stress was reduced to a statistically nonsignificant level. In similar models, the change in a participant's economic situation was not associated with decreased alcohol consumption (table 5), incident diseases, or increased body mass index.

\section{Discussion}

Economic trends cause wide fluctuations in the demand for labour in the construction industry. During the Finnish recession of the early 1990s, nearly $50 \%$ of construction workers were jobless at one point. In our study, the participants were employed at the time of the first interview, but only $20 \%$ remained employed during the entire 4 year follow up.

It has been argued that when the unemployment rate is high, individual characteristics are of less importance in relation to job loss than when under more favourable conditions; mortality statistics give credence to this. ${ }^{8}$ We identified some predictors of unemployment even during mass redundancy. However, we could predict unemployment, particularly short term, only to a minor extent. ${ }^{13}$ Thus, unemployment is mostly determined by other factors such as economic hardship, bankruptcy, and perhaps personal factors that were not addressed.

\section{Health and lifestyle factors as predictors of unemployment}

The stability of the participants' employment history, marital status, and some lifestyle and health characteristics independently predicted long term unemployment. It was not possible to estimate the extent to which these increased the probability of job loss or decreased the chance of re-employment. However, as most of the variables had predictive value only in relation to long term unemployment, it seems that the latter was mostly the case.

It is possible that employers consider marital status when deciding about employment. It is also possible that individuals with a family want to maximise their income and actively seek re-employment, but as the association was not confined to married or cohabiting workers it may reflect a more general factor. Excessive 
alcohol consumption poses potential problems for work output, occupational safety, and cooperation. Also a worker consuming excess alcohol may be less motivated to seek another job. Smoking could indicate risk taking and even susceptibility to accidents. ${ }^{14}$ It seems more probable that smoking is intricately entwined with an individual's life history. ${ }^{15}$

Our results support the hypothesis of unemployment being selective according to an individual's health: when other factors were accounted for, mental disorders, skin disorders, and stress symptoms were predictive of long term unemployment. Gastrointestinal disorders lost significance as predictors when smoking and alcohol consumption were accounted for; these may have contributed to the diseases.

Unemployment was not associated with educational level, but this could have been due to the low variation in education among the participants. That work related strain, both physical and mental, and work ability were not associated with unemployment is interesting considering the physical strenuousness of construction work: how work was perceived by the employee was not of importance in relation to unemployment.

\section{Diseases and stress}

Participants who were unemployed long term reported less incident diseases than the rest of the cohort. The finding is at variance with earlier reports. ${ }^{4-6}$ Finnish people have universal access to health care, and it is unlikely that the reduced economic resources of unemployed workers would have greatly affected the probability of them consulting a physician; the empirical evidence supported this. As occupational health services were no longer available to the unemployed worker, perhaps an unwillingness to seek care elsewhere was a factor here. Another possibility is that the reduction in work load and other work exposures influenced seeking care or even morbidity.

It has been assumed that a person finds losing a job less stressful when the rate of general unemployment is high. ${ }^{16}$ In our study, stress increased among the unemployed workers during a period of mass redundancy and did not level off when duration of unemployment increased. A chronic state of stress may lead to physical and mental morbidity. Thus a longer follow up of our cohort might have shown other health consequences.

\section{Lifestyle changes}

Increased stress among the unemployed workers did not lead to increased alcohol consumption. ${ }^{17}$ As with previous findings, alcohol consumption decreased with increasing duration of unemployment, perhaps due to the change in work and leisure routine: diminished economic resources were not of importance. Becoming unemployed may have different effects on health behaviour depending on the individual's age. Reports on the adverse effects of unemployment on lifestyle have been in young people. ${ }^{18} 19$

It was not possible for us to study changes in smoking habits, but in another prospective series of Finnish construction and forest workers around the same period, the proportion of regular smokers decreased with unemployment. ${ }^{20}$ The increase in exercise frequency observed by us may be because the construction workers are accustomed to high physical
- Among middle aged construction workers, long term unemployment was predicted by an unstable occupational history, health problems, smoking, high alcohol consumption, low body mass index, and being single

- Stress predicted long term unemployment, which further increased the level of stress

- Men unemployed long term reported increased exercise and decreased alcohol consumption, but increased body mass index, and fewer incident diseases than the rest of the cohort

- Changes in personal economic situation with unemployment mediated the effect of unemployment on stress but not on alcohol consumption

activity. Health campaigns directed at unemployed people have also promoted exercise as a means of preserving work ability. Despite increased physical activity during leisure time and decreased alcohol consumption, the unemployed workers tended to become more obese than the rest of the cohort. A similar finding has been reported in middle aged British men. ${ }^{17}$

\section{Generalisability of results}

Our findings may not be generalisable to other types of employment. In construction work, repeat short periods of unemployment are common owing to seasonal and other variations in construction activity, and unemployment may not be as much a threat to occupational identity $^{21}$ as it would be to workers in more stable employment (a more profound increase in stress might be expected if such workers are made redundant). In terms of the comparative increase in economic hardship, one mechanism of increased stress and ill health, ${ }^{62}$ the consequences are comparable.

One limitation of our study was that all information was self reported, although the data were obtained by trained interviewers. The baseline interview was conducted at the workplace, but follow up information was obtained by telephone. Any bias concerns the follow up data and should not affect comparisons within it. To increase the reliability of information on the duration of unemployment, this was assessed separately for each year of follow up and then summed.

In conclusion, selection to long term unemployment according to poor health, particularly mental health, was evident. The association of stress with unemployment was reciprocal: stress predicted unemployment, which further increased the level of stress. High alcohol consumption and smoking predated becoming jobless, but favourable lifestyle changes were observed among unemployed workers.

We thank Timo Aitta, and Risto Hagman for scoring the responses for alcohol consumption.

Contributors: EM conceived the study and, with PL-A and $\mathrm{AM}$, contributed to its design. PL-A and PM analysed the data and, with JL and AM, interpreted the results. PL-A and JL wrote the introduction, PL-A, EM, and PM wrote the methods, PL-A and PM wrote the results, and PL-A, JL, and AM wrote the discussion. PL-A and JL will act as guarantors for the paper.

Funding: Finnish Work Environment Fund.

Competing interests: None declared. 
1 Morris JK, Cook DG. A critical review of the effect of factory closures on health. BrJ Ind Med 1991;48:1-8.

2 Hallsten L. Mental health and unemployment. On health-based selection to work. Arbete och Hälsa 1998:7. (Dissertation in Swedish with English abstract.)

3 Weich S, Lewis G. Poverty, unemployment, and common mental disorders: population based cohort study. BMJ 1998;317:115-9.

4 Elkeles T, Seifert W. Unemployment and health impairments. Eur J Public Health 1993;3:28-37.

5 Jin RL, Shah CH, Svoboda TJ. The impact of unemployment on health: a review of the evidence. Can Med Assoc J 1995;153:529-40.

6 Mathers CD, Schofield DJ. The health consequences of unemployment: the evidence. Med J Aust 1998;168:178-82.

7 Bethune A. Economic activity and mortality of the 1981 census cohort in the OPCS longitudinal study, Popul Trends 1996;83:37-42.

8 Martikainen P, Valkonen T. Excess mortality of unemployed men and women during a period of rapidly increasing unemployment. Lance 1996;348:909-12.

9 Bartley M. Unemployment and ill health: understanding the relationship. JEpidemiol Community Health 1994;48:333-7.

10 Avery AJ, Betts DS, Whittington A, Heron TB, Wilson SH, Reeves JP. The mental and physical health of miners following the 1992 national pit closure programme: a cross sectional survey using general health questionnaire GHQ-12 and short form SF-36. Public Health 1998;112:169-73.

11 Matikainen E, Liira J, Rytkönen H. Health, work ability and working conditions of construction workers. Study design and follow-up in 1991-1995. Työ ja ihminen 1998;12:85-93, 152. (In Finnish with English abstract.)

12 S-PLUS 4 guide to statistics. Seattle: Data Analysis Products, Math Soft, 1997.
13 Leino-Arjas P, Liira J, Mutanen P, Malmivaara A, Matikainen E Unemployment, health and health behaviour of construction workers. Työ ja ihminen 1998;12:139-48, 155. (In Finnish with English abstract.)

14 Ryan J, Zwerling C, Jones M. Cigarette smoking at hire as a predictor of employment outcome. J Occup Environ Med 1996;38:928-33.

15 Lee AJ, Crombie IK, Smith WCS, Tunstall-Pedoe HD. Cigarette smoking and employment status. Soc Sci Med 1991;33:1309-12.

16 Dooley D, Catalano R. Unemployment as a stressor: findings and implications of a recent study. In: Badura B, Kickbusch I, eds. Health promotion research. Towards a new social epidemiology. Copenhagen: WHO Regional Publications, 1991:313-39. (European series No 37.)

17 Morris JK, Cook DG, Shaper AG. Non-employment and changes in smoking, drinking, and body weight. BMJ 1992;304:536-41.

18 Janlert U, Hammarström A. Alcohol consumption among unemployed youths: results from a prospective study. Br J Addict 1992;87:703-14.

19 Montgomery SM, Cook DG, Bartley MJ, Wadsworth M. Unemployment, cigarette smoking, alcohol consumption and body weight in young British men. Eur J Publ Health 1998;8:21-7.

20 Liira J, Leino-Arjas P. Unemployment in construction and forest work. Predictors and consequences in a 5-year follow-up. Scand J Work Environ Health 1999;25:42-9.

21 Ezzy D. Unemployment and mental health: a critical review. Soc Sci Med 1993:37:41-52.

22 Lynch JW, Kaplan GA, Shema SJ. Cumulative impact of sustained economic hardship on physical, cognitive, psychological, and social functioning. New Engl J Med 1997;337:1889-95.

(Accepted 2 June 1999)

\title{
Doctors as patients: postal survey examining consultants and general practitioners adherence to guidelines
}

\author{
Malcolm Forsythe, Michael Calnan, Barbara Wall
}

\begin{abstract}
Objectives To examine the adherence by senior NHS medical staff to the BMA guidelines on the ethical responsibilities of doctors towards themselves and their families.

Design Postal semistructured questionnaire.

Setting Four randomly selected NHS trusts and three local medical committees in South Thames region.

Subjects Consultants and principals in general practice.

Main outcome measures Personal use of health services.

Results The response rate was 64\% (724) for general practitioners and $72 \%$ (427) for consultants after three mailings. Most $(1106,96 \%)$ respondents were registered with a general practitioner, although little use was made of their services. 159 (26\%) general practitioners were registered with a general practitioner in their own practice and $80(11 \%)$ admitted to looking after members of their family. 73 (24\%) consultants would never see their general practitioner before obtaining consultant advice. Most consultants and general practitioners admitted to prescribing for themselves and their family. Responses to vignettes for different health problems indicated a general reluctance to take time off, but there were differences between consultants and general practitioners and by sex. Views on improvements needed included the possibility of a "doctor's doctor," access to out of area secondary care, an occupational health service for general practitioners, and regular health check ups.
\end{abstract}

Conclusion The guidelines are largely not being followed, perhaps because of the difficulties of obtaining access to general practitioners outside working hours. The occupational health service should be expanded and a general practitioner service for NHS staff piloted.

\section{Introduction}

Mortality data show that compared with the general male population doctors have a significantly lower mortality ratio, but deaths from specific causes such as suicide and external injury and poisoning are significantly higher. ${ }^{1}$ More recent evidence shows that male doctors (aged 20-74) have a significantly higher proportional mortality ratio for viral hepatitis, liver cancer, and cirrhosis and women doctors (aged 20-74) have a higher ratio for cancer of the pancreas. Research into morbidity is dominated by measuring levels of stress, anxiety, and depression and the possible causes. ${ }^{3-9}$ The picture emerging is of general practitioners and senior hospital doctors with high levels of stress, anxiety, and depression who take very little time off work for illness but who, when they are off work, tend to be off for long periods.

The Nuffield Trust report in 1994 showed serious shortcomings in the services available and the way in which doctors treat themselves and their colleagues. ${ }^{10}$ Recognising this, the BMA produced in 1995 a set of guidelines on the ethical responsibilities of doctors towards themselves and their families and to other doctors as patients. ${ }^{11}$ These have subsequently been endorsed by the Academy of Royal Medical Colleges ${ }^{12}$ and the General Medical Council. ${ }^{13}$ We studied the
Centre for Health Services Studies, George Allen Wing, University of Kent, Canterbury, Kent CT2 7NF

Malcolm Forsythe professorial fellow in public health

Michael Calnan director

Barbara Wall research officer M Forsythe J.M.Forsythe-2@ ukc.ac.uk

BMJ 1999;319:605-8

website

extra

More details of the questions put to participants are available on the $B M J$ 's website

www.bmj.com 